\title{
The Impact of Operational Conditions on Commercial Membranes using in Removing Nitrate from Drinking Water
}

\author{
Mudar Harfoush ${ }^{1 *}$
}

${ }^{1}$ Department of Environmental Engineering, K. N. Toosi University of Technology, Tehran 1996715433, IRAN
*Corresponding Author: harfoush@email.kntu.ac.ir

Citation: Harfoush, M. (2020). The Impact of Operational Conditions on Commercial Membranes using in Removing Nitrate from Drinking Water. Aquademia, 4(1), ep20014. https://doi.org/10.29333/aquademia/8225

\section{ARTICLE INFO}

Received: 28 Apr. 2020

Accepted: 29 Apr. 2020

\begin{abstract}
It is a great advantage to reduce the energy requirement for the provision of consumable groundwater to an absolute minimum. Reverse osmosis (RO) and nanofiltration (NF) are two of the most commonly used technologies for desalination water to provide potable water with lowest energy consumption. However, there is still lack of a thorough comparison between these two methods providing the better option in different conditions. Therefore, in this paper, nitrate rejection and the effects of operation conditions on the performance of RO and NF systems are compared. Several wells in Zarch District, Iran, are polluted by nitrate and groundwater is a major drinking water source in the region. The aim of this research was to evaluate the efficiency of nitrate removal by two commercial membranes NF90 and BW30 (both Dow Filmtec) using natural water under different operating conditions. Experiments were conducted to assess the influence of temperature and pressure on nitrate removal by the membranes. The results indicated that BW30 (reverse osmosis) performs better removing nitrate

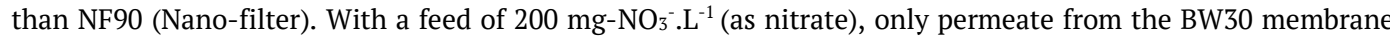
met the required quality standard for drinking purposes $\left(50 \mathrm{mg}-\mathrm{NO}_{3} \cdot \mathrm{L}^{-1}\right)$. When the feed concentration increased to $250 \mathrm{mg}-\mathrm{NO}_{3}{ }^{-} \cdot \mathrm{L}^{-1}$, both membranes failed to achieve the standard in the permeate. The membranes showed similar nitrate removal behaviour under different applied temperatures and pressures. It was concluded that the BW30 membrane can be used to produce drinking water in the study area with influent concentrations below 200 $\mathrm{mg}-\mathrm{NO}_{3} \cdot \mathrm{L}^{-1}$.
\end{abstract}

Keywords: drinking water, nanofiltration, nitrate, reverse osmosis

\section{INTRODUCTION}

Water is the main vital factor not for humans but every living organism. In spite of its effect on the ecosystem, it plays an important role in energy supply. Every power plant with reproducible energy sources like wind turbine generators, hydroelectric power stations, wave energy converters, tidal power plants, geothermal energy plants, even fossil fuel power plants need water with certain properties. Recently, substantial researches have been dedicated to the development of methods for the revival, rejuvenation, and conservation of water resources with minimum cost and energy consumption. Nitrate is one of the most important polluting factors which should be removed from drinking water with an optimum amount of energy.

The groundwater in Zarch District, Iran, is contaminated with nitrate but is also a major drinking water resource. Zarch is in Yazd County, at $32^{\circ} 6^{\prime} 2.16^{\prime \prime} \mathrm{N}, 54^{\circ} 26^{\prime} 3.12^{\prime \prime}$ E. The climate is semi-arid with less than $60 \mathrm{~mm}$ average annual precipitation - e.g., as recorded in 2016 (Iran Meteorological Organization,
2016). According to the most recent census, the area has a population of around 20,000 with poor access to clean water (Statistical Center of Iran, 2011). Thus, groundwater management is a challenge for the local water supply authority, which has to deal with around 4,000 households mainly classified as rural settlements in the region. It is estimated that about $28801 . \mathrm{d}^{-1}$ is required, as average domestic water usage per capita is $13.481 . \mathrm{d}^{-1}$.

Nitrate is classified as toxic to humans, and excessive amounts in drinking water can result in health issues including methaemoglobinaemia and cancer (Ward et al., 2018). Because of this, the maximum acceptable concentration (MAC) of nitrate in drinking water has been set to $50 \mathrm{mg}-\mathrm{NO}_{3}{ }^{-} . \mathrm{L}^{-1}$ in the Iranian Water Quality Standards (ISIRI, 2009). Since the standard's application in the study area was the main focus of this research, $50 \mathrm{mg}-\mathrm{NO}_{3}{ }^{-} . \mathrm{L}^{-1}$ was considered the primary goal for nitrate removal from groundwater.

The nitrate removal efficiency of nano-filter (NF) and reverse osmosis (RO) membranes depends on several parameters including pore size, membrane structure, and water quality. Both types can remove nitrate from water 
Table 1. Major ion concentrations in the ground water

\begin{tabular}{cc}
\hline Constituent & Concentration (mg. $\mathbf{L}^{-\mathbf{1}}$ ) \\
\hline $\mathrm{Ca}^{+2}$ & 72 \\
\hline $\mathrm{Mg}^{+2}$ & 64 \\
\hline $\mathrm{Na}^{+}$ & 710 \\
\hline $\mathrm{Cl}^{-}$ & 1,150 \\
\hline $\mathrm{SO}^{-2}$ & 380 \\
\hline $\mathrm{K}^{+}$ & 8 \\
\hline $\mathrm{NO}_{3}{ }^{-}$ & 40 \\
\hline $\mathrm{SiO}_{2}$ & 9 \\
\hline
\end{tabular}

because of the sieve effect - the nitrate ion has a hydrated radius of $0.335 \mathrm{~nm}$ and molecular weight of 62 g.mol ${ }^{-1}$ (Nightingale, 1959). However, membrane charge plays a significant role in membrane performance because of electrostatic repulsion between the ions and the membrane surface (Childress \& Elimelech, 2000). In addition, the ion content of groundwater differs from one place to another, so membrane performance must differ as well. In this study, two commercial membranes - NF90 and BW30 - were chosen for experimental work for several reasons. First, both are negatively charged, as is the nitrate ion. As a result, relatively higher nitrate rejection is expected with charged rather than uncharged membranes. Second, NF90 has been shown to have a nitrate rejection rate exceeding $80 \%$ (Garcia et al., 2006; Hoinkis et al., 2011; Mogheir et al., 2014; Santafé-Moros et al., 2005). The potential applications of Nanofiltration (NF) have increased recently, because of some advantages such as higher flux, which means lower energy consumption, and lower rejection of monovalent ions (Haotian Zhu et al., 2017). Because of this, it was worth evaluating this membrane's behaviour in relation to groundwater in the study area. On the other hand, the nitrate removal behaviour of the BW30 membrane, which has a smaller pore size, has been not investigated in relation to groundwater. And besides, RO system uses less energy than the nanofiltration system, leading to a decrease in overall costs, and allowing to use of RO technology much more economically than other technologies (Kimmo Arola et al., 2019).

The study's main goal was thus to evaluate the nitrate rejection efficiency of the NF90 and BW30 membranes at pilotscale using groundwater under different operating conditions.

\section{MATERIALS AND METHODS}

\section{Feed Water Quality}

The experiments were conducted with two different feed solutions as: 1) potable water with $\mathrm{EC}=7 \mu \mathrm{S} . \mathrm{cm}^{-1}$, and 2) groundwater samples, were collected from a well in Zarch District. The composition of this groundwater is shown in Table 1. The potable water was only used for permeability testing before the experimental series, to ensure functional capability. To provide the desired nitrate concentrations (50 to $300 \mathrm{mg}-\mathrm{NO}_{3}-\mathrm{L}^{-1}$ ), a solution of $\mathrm{NaNO}_{3}$ (Sigma-Aldrich) was added to the groundwater samples. Nitrate concentrations were determined using standard method $4500 \mathrm{NO}_{3}{ }^{-}$nitrogen $\mathrm{E}$ (cadmium reduction) (Baird et al., 2012).

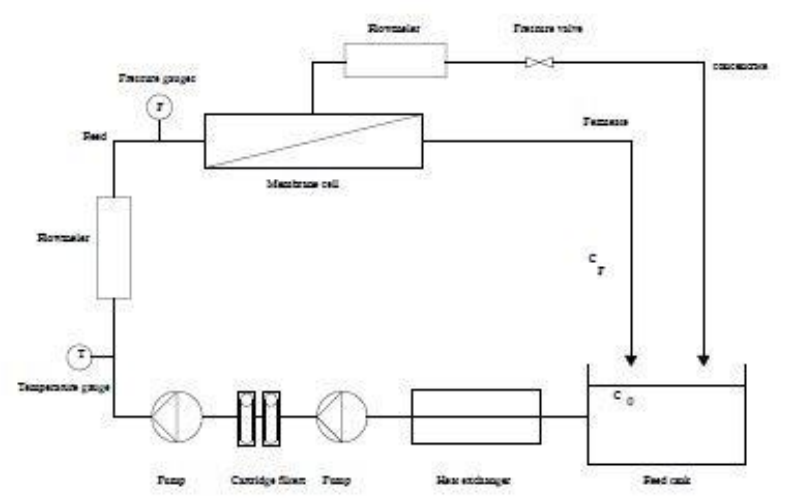

Figure 1. Schematic layout of the pilot-scale membrane system

Table 2. Membrane specifications

\begin{tabular}{ccc}
\hline & \multicolumn{2}{c}{ Type } \\
\cline { 2 - 3 } & NF90-4040 & BW30-4040 \\
\hline Maximum Pressure & $4.1 \mathrm{MPa}$ & $4.1 \mathrm{MPa}$ \\
\hline Maximum Temperature & $318 \mathrm{~K}$ & $318 \mathrm{~K}$ \\
\hline Membrane Active Area & $7.6 \mathrm{~m}^{2}$ & $7.2 \mathrm{~m}^{2}$ \\
\hline Contact Angle & $100\left(^{\circ}\right)$ & $100\left(^{\circ}\right)$ \\
Zeta potential & -15 to $-30 \mathrm{mV}$ & $-6 \mathrm{mV}$ \\
\hline Surface Charge & Negative & Negative \\
\hline MWCO (Da) & 200 & 90 \\
\hline Maximum Flux Rate & $86.81 \times 10^{-3}{\mathrm{~L} . \mathrm{s}^{-1}}^{-}$ & $104.16 \times 10^{-3}{\mathrm{~L} . \mathrm{s}^{-1}}^{-1}$ \\
\hline pH range in cleaning & $1-12$ & $1-13$ \\
\hline Continuous Operating pH range & $2-12$ & $2-11$ \\
\hline Free Chlorine Tolerance & $0.1 \mathrm{mg} . \mathrm{L}^{-1<}$ & $0.1 \mathrm{mg} \cdot \mathrm{L}^{-1<}$ \\
\hline
\end{tabular}

\section{Pilot Plant}

The experiments were carried out on a pilot plant operated in batch recirculation mode, with both permeate and concentrate returned to the feed tank (see Figure 1). The feed tank capacity was 3001 of which only around $80 \%$ was used during the experiments. To inhibit membrane clogging, a $5 \mu \mathrm{m}$ cartridge filter was used. Composite, spiral-wound, polyamide membranes - NF90-4040 and BW30-4040 - were used, both manufactured by Dow Filmtec. Their full specifications are presented in Table 2.

\section{Experimental Conditions}

The parameters studied included especially, feed water concentration, operating pressure, temperature, and permeate flux. The influence of feed water concentration on nitrate removal was investigated using a range of concentrations - 50, 150, 200, 250, and $300 \mathrm{mg}-\mathrm{NO}_{3}{ }^{-} \cdot \mathrm{L}^{-1}$, whereas constant temperature $(298 \mathrm{~K})$, pressure $(0.9 \mathrm{MPa})$, and $\mathrm{pH}(8)$ were used.

The effect of pressure was studied over the range 0.5 to 15 $\mathrm{MPa}$, at constant temperature of $298 \mathrm{~K}, \mathrm{pH}$ of 8 , and concentration of $100 \mathrm{mg}-\mathrm{NO}^{-3} \cdot \mathrm{L}^{-1}$ in the influent.

Temperature was investigated over the range 295 to $310 \mathrm{~K}$, at constant pressure of $0.9 \mathrm{MPa}, \mathrm{pH}$ of 8 , and influent concentration of $100 \mathrm{mg}-\mathrm{NO}^{-3} \cdot \mathrm{L}^{-1}$. In this research, the flux rate was recorded only for permeability tests before the experimental series with groundwater samples to check the functional capability of the membranes. A similar approach 


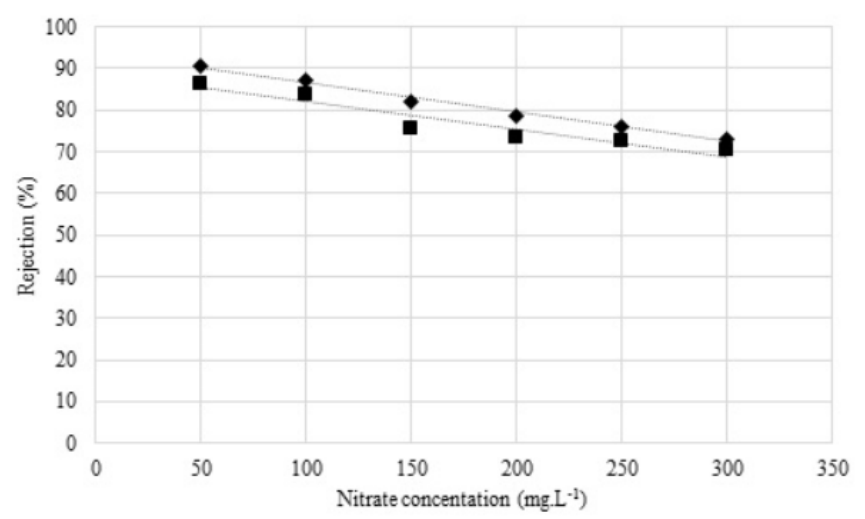

Figure 2. Nitrate rejection by NF90 and BW30 membranes: (匹) $\mathrm{NF} 90$ and $(\diamond)$ BW30. In both cases, pressure $=0.9 \mathrm{MPa}$; temperature $=298 \mathrm{~K} ; \mathrm{pH}=8$

has been used by others (Santafé-Moros et al., 2005). The rates observed were used to calculate the permeate flux.

\section{Calculation of Permeate Flux and Rejection Efficiency}

The permeate flux (Jp) and water flux $\left(\mathrm{J}_{\mathrm{w}}\right)$ were calculated using Equation (1):

$$
J_{w}\left(J_{P}\right)=V / S * t
$$

where $\mathrm{V}$ is the permeate volume, $\mathrm{S}$ the membrane area, and $\mathrm{t}$ the time needed for $\mathrm{V}$ to permeate the NF or RO membrane. The permeate volume and the time required were recorded during the permeability test using potable water samples. Rejection efficiency depends on several factors including membrane characteristics, feed water characteristics (e.g. temperature, ion concentrations), and operating conditions. In this research, rejection efficiency was determined from the concentration of the feed and permeates solutions using Equation (2):

$$
R(\%)=\left(1-\left(C_{p} / C_{o}\right)\right) \times 100
$$

where $\mathrm{R}$ is the rejection efficiency (\%), $\mathrm{C}_{\mathrm{p}}$ permeate nitrate concentration $\left(\mathrm{mg}-\mathrm{NO}_{3}-\mathrm{L}^{-1}\right)$, and $\mathrm{C}_{0}$ the feed nitrate concentration. Equation 2 has been used by others to calculate rejection efficiency (Garcia et al., 2006; Richards et al., 2010; Santafé-Moros et al., 2005).

\section{RESULTS AND DISCUSSION}

\section{Effects of Concentration on Nitrate Removal}

Figure 2 shows nitrate removal efficiency versus applied concentrations for the NF90 and BW30 membranes. The maximum NF90 and BW30 nitrate removal rates were 90.7 and $86.4 \%$, respectively. The BW30 membrane was relatively more efficient at all concentrations tested than the NF90 membrane, because of its smaller pore size (Table 2) and its structure. Similar nitrate removal performance has been reported for the BW30 membrane, with $85 \%$ nitrate rejection achieved using a model solution (Richards et al., 2010). In this study, rejection declined from 86.4 to $70.4 \%$ and 90.7 to $73.1 \%$ for NF90 and BW30 membranes, respectively, as the feed concentrations increased from 50 to $300 \mathrm{mg}^{-\mathrm{NO}^{-}}{ }_{3} \cdot \mathrm{L}^{-1}$.

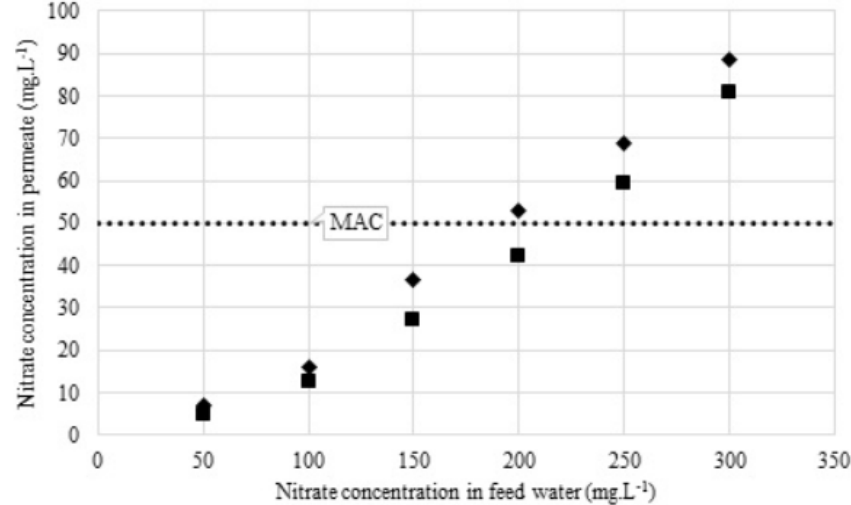

Figure 3. NF90 and BW30 permeate nitrate concentrations. (匹) NF90 membrane, and $(\diamond)$ BW30 membrane. Operating conditions as in Figure 2

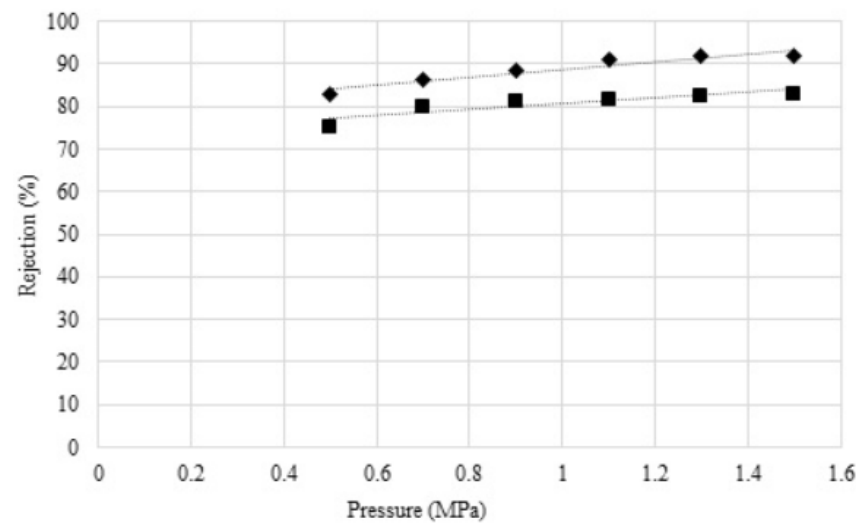

Figure 4.Nitrate rejection results for NF90 and BW30 membranes under different operating pressures: (a) NF90 membrane, and $(\diamond)$ BW30 membrane. Feed concentration 100 mg-NO3-289.L-1, other operating conditions as in Figure 2.

Both membranes showed a strong relationship between nitrate removal and feed nitrate concentration for all conditions applied. This behavior has been reported by other scholars for the nitrate removal with charged membrane (Santafé-Moros et al., 2005). As application for drinking water use was the study's main focus, the permeate nitrate concentration should not exceed $50 \mathrm{mg} . \mathrm{L}^{-1}$. Both membranes satisfied this requirement when the feed concentration was less than $150 \mathrm{mg}-\mathrm{NO}_{3}{ }^{-} \cdot \mathrm{L}^{-1}$. The BW30 membrane also achieved it using $200 \mathrm{mg}-\mathrm{NO}_{3}-\mathrm{L}^{-1}$ feed concentration. However, neither membrane met the requirement when the feed water concentration exceeded $200 \mathrm{mg}-\mathrm{NO}_{3}^{-} \cdot \mathrm{L}^{-1}$, so, in such cases, additional processing would be required for potable purposes.

\section{Effects of Operating Pressure on Nitrate Removal}

Figure 4 shows the proportional nitrate rejection by the two membranes under different operating pressures. Maximum removal efficiency occurred at the maximum operating pressure (1.5MPa), with $82.9 \%$ and $92 \%$ achieved by NF90 and BW30, respectively. As the pressure was increased from 0.5 to $1.5 \mathrm{MPa}$, rejection efficiency rose from $75.1 \%$ to $82.9 \%$ and $82.7 \%$ to $92 \%$ for NF90 and BW30, respectively. A linear relationship was observed between pressure and rejection rate under all applied conditions - (Figure 4) - and no concentration polarization was observed. This linear 


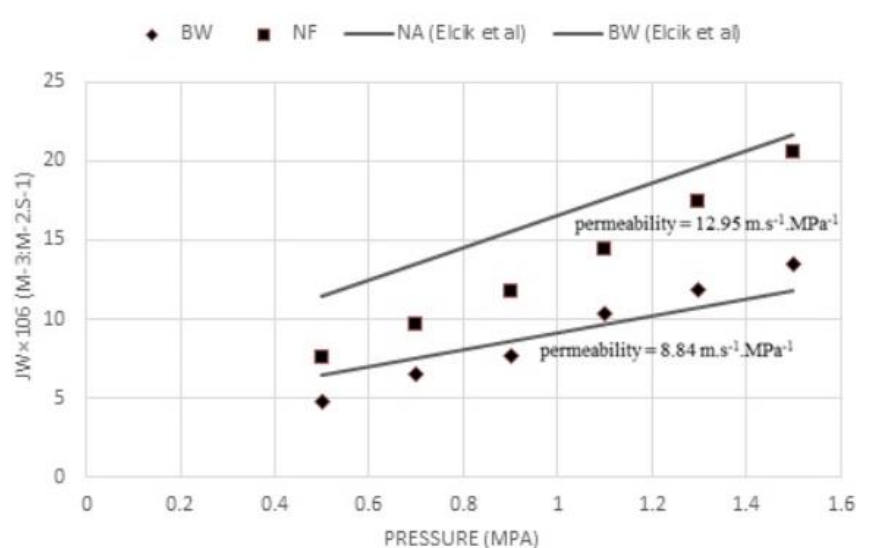

Figure 5. Permeate fluxes for NF90 and BW30 at different operating pressures. ( $\bullet$ NF90, and $(\diamond)$ BW30. (Conditions treated water; temperature $298 \mathrm{~K}$; pH 8.)

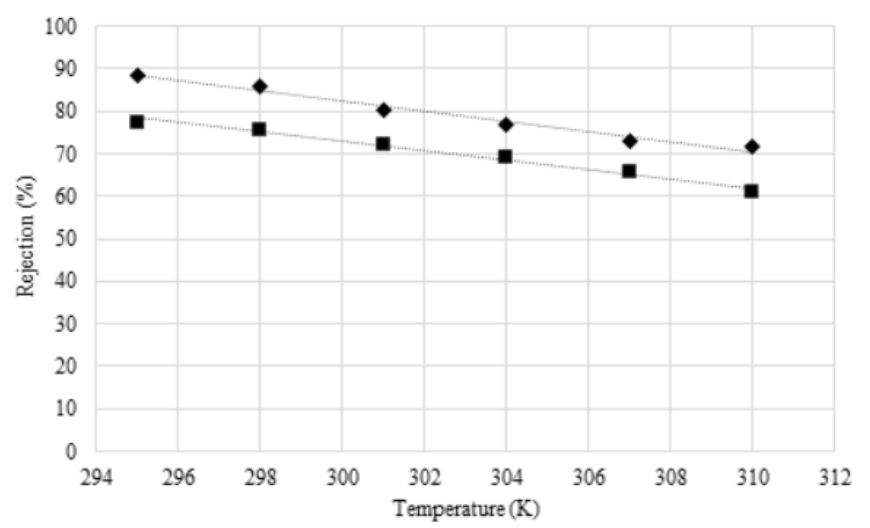

Figure 6. Nitrate rejection rates at different operating temperatures; ( $($ ) NF90 membrane and $(\diamond)$ BW30 membrane. For both membranes - 100 mg-NO3-.L-1 groundwater; $\mathrm{pH}=8$; pressure 0.9 $\mathrm{MPa}$

nitrate removal trend has been observed by others for the NF90 membrane (Garcia et al., 2006; Santafé-Moros et al., 2005). Interestingly, the BW30 membrane showed similar nitrate removal behaviour under applied pressure. Thus, when better nitrate removal efficiency is required, the BW30 membrane used at higher pressure can be considered as a treatment option.

\section{Effects of Operating Pressure on Permeate Flux}

The permeate flux rates versus applied pressure for the membranes are presented in Figure 5. This figure also shows that there is a good agreement in the results of the present work with others (Elcik et al., 2015). Maximum fluxes were observed at $1.5 \mathrm{MPa}$, with treated water, with rates of $20.55 \times$ $10^{-6}$ and $13.44 \times 10^{-6} \mathrm{~m} . \mathrm{s}^{-1}$ obtained from NF90 and BW30, respectively. As the pressure fell from 1.5 to $0.5 \mathrm{MPa}$, the flux rate fell from $20.55 \times 10^{-6}$ to $7.61 \times 10^{-6} \mathrm{~m} . \mathrm{s}^{-1}$ and $13.44 \times 10^{-6}$ to $4.81 \times 10^{-6} \mathrm{~m} . \mathrm{s}^{-1}$ for the NF90 and BW30 membranes, respectively. (The treated water permeability values were $12.95 \times 10^{-6}$ and $8.84 \times 10^{-6} \mathrm{~m} \cdot \mathrm{s}^{-1} \cdot \mathrm{MPa}^{-1}$ for NF90 and BW30, see Figure 5).

\section{Temperature Effects on Nitrate Removal}

Figure 6 shows the observed effects of temperature on nitrate rejection. For both membranes, the maximum nitrate rejection rate was observed at $295 \mathrm{~K}-60.8 \%$ and $71.6 \%$ for NF90 and BW30, respectively. As the temperature increased from 295 to $310 \mathrm{~K}$, the NF90 and BW30 nitrate rejection rates declined from $77.4 \%$ to $60.8 \%$ and 83.4 to $72.4 \%$, respectively, probably because of changes in the water's kinematic viscosity - an increase in temperature causes a decrease in osmotic pressure. Torabian et al. (2009) reporting on the NF90 membrane note that its nitrate removal efficiency dropped from $82 \%$ to $75 \%$ with increasing temperature from $290 \mathrm{~K}$ to $300 \mathrm{~K}$. Linear relationships between nitrate rejection and temperature were observed under all operating conditions applied for both membranes - in other words, no significant structural change was detected in membrane pores.

\section{Uncertainty Analysis}

Experiments were conducted several times to provide uncertainty analysis for the results and ensure that the data was taken from each test is reliable. Table 3 demonstrates the data for tests correspond to the effect of feed concentration on nitrate removal. The sixth column in Table 3 shows the average value of four tests, and the final column shows the standard deviation of the output concentrations. The standard deviation of $\mathrm{C}_{\mathrm{i}}$, STD, measures dispersion of data and is capable of comparing dispersion degrees of concentrations for both NF90 and BW30 as membrane with different mean values. It is defined as Equation (3):

$$
S T D=\left(\frac{1}{n} \sum_{i=1}^{n}\left(C_{i}-\frac{1}{n} \sum_{i=1}^{n} C_{i}\right)^{2}\right)^{\frac{1}{2}}
$$

It can be seen from Table 3 that the deviation of data from the average values is insignificant, because the standard deviation of nitrate concentration permeates is small.

\section{CONCLUSIONS}

The nitrate removal efficiency of NF90 and BW30 membranes was examined using groundwater samples from the Zarch District in Iran. The results indicate that neither membrane can be considered as a treatment option in the

Table 3. Experimental data analysis

\begin{tabular}{|c|c|c|c|c|c|c|c|c|c|c|c|c|c|}
\hline \multirow{2}{*}{\multicolumn{2}{|c|}{$\begin{array}{l}\text { Nitrate in permeate } \\
\left(\mathrm{mg} \cdot \mathrm{L}^{-1}\right)\end{array}$}} & \multicolumn{2}{|c|}{ Test1 } & \multicolumn{2}{|c|}{ Test2 } & \multicolumn{2}{|c|}{ Test3 } & \multicolumn{2}{|c|}{ Test4 } & \multicolumn{2}{|c|}{ average } & \multicolumn{2}{|c|}{ STD } \\
\hline & & NF & BW & NF & BW & NF & BW & NF & BW & NF & BW & NF & BW \\
\hline \multirow{6}{*}{$\begin{array}{c}\text { Feed } \\
\text { concentration }\end{array}$} & 50 & 6.65 & 4.53 & 6.95 & 4.72 & 6.71 & 4.48 & 6.89 & 4.67 & 6.8 & 4.6 & 0.12 & 0.098 \\
\hline & 100 & 15.95 & 12.4 & 16.18 & 12.87 & 16.25 & 12.53 & 16.02 & 13.0 & 16.1 & 12.7 & 0.12 & 0.244 \\
\hline & 150 & 35.5 & 25.93 & 36.14 & 26.84 & 37.3 & 28.07 & 36.76 & 27.16 & 36.4 & 27 & 0.66 & 0.765 \\
\hline & 200 & 51.73 & 42.0 & 53.09 & 41.13 & 53.87 & 43.67 & 52.51 & 42.6 & 52.8 & 42.4 & 0.78 & 0.909 \\
\hline & 250 & 67 & 58.7 & 68.5 & 59.77 & 70.5 & 58.83 & 70 & 60.7 & 69 & 59.5 & 1.37 & 0.806 \\
\hline & 300 & 88.1 & 81.46 & 87.63 & 82.0 & 89.97 & 79.4 & 89.5 & 79.94 & 88.8 & 80.7 & 0.96 & 1.065 \\
\hline
\end{tabular}


study area under some operating conditions. The membranes behaved similarly as applied pressures and temperatures varied. In all experiments with feed nitrate concentrations below $150 \mathrm{mg}-\mathrm{NO}_{3} \cdot \mathrm{L}^{-1}$, both membranes rejected nitrate sufficiently well to achieve the drinking water MAC. However, the BW30 membrane always achieved better nitrate removal and achieved the MAC from feed containing $200 \mathrm{mg}-\mathrm{NO}_{3}-\mathrm{L}^{-1}$ (see Figure 3). At feed concentrations exceeding $200 \mathrm{mg}-\mathrm{NO}_{3}$ . $\mathrm{L}^{-1}$, neither membrane achieved the MAC. However, both membranes can be considered for use for nitrate reduction (50 to $\left.100 \mathrm{mg}-\mathrm{NO}_{3} \cdot \mathrm{L}^{-1}\right)$ in non-potable water applications.

In the current study, a detailed comparison is provided between the efficiency of NF90 membrane and BW30 membrane for nitrate removal from drinking water and the results show that there are some improvements in nitrate removal by using BW30 as the membrane.

\section{ACKNOWLEDGEMENTS}

The authors are grateful to the local water authority in the Zarch District for providing data and documents.

\section{REFERENCES}

Arola, K., Van der Bruggen, B., Mänttäri, M., \& Kallioinen, M. (2019). Treatment options for nanofiltration and reverse osmosis concentrates from municipal wastewater treatment: A review, Critical Reviews in Environmental Science and Technology 49(22), 2049-2116. http://doi.org/ 10.1080/10643389.2019.1594519

Baird, R. B., Eaton, A. D., \& Clesceri, L. S. (2012). Standard methods for the examination of water and wastewater (Vol. 10). E. W. Rice (Ed.). American Public Health Association, Washington DC, USA.

Childress A. E., \& Elimelech, M. (2000). Relating Nanofiltration Membrane Performance to Membrane Charge (Electrokinetic) Characteristics. Environmental Science \& Technology, 34(17), 3710-3716. http://doi.org/ 10.1021/es0008620

Elcik, H., Celik, S. O., Cakmakci, M., \& Özkaya, B. (2015). Performance of Nanofiltration and Reverse Osmosis Membranes for Arsenic Removal from Drinking Water. Desalination and Water Treatment, 57(43), 20422-20429. http://doi.org/10.1080/19443994.2015.1111812

Garcia, F., Ciceron, D., Saboni, A., \& Alexandrova, S. (2006). Nitrate Ions Elimination from Drinking Water by Nanofiltration: Membrane Choice. Separation and Purification Technology, 52(1), 196-200. http://doi.org/ 10.1016/J.SEPPUR.2006.03.02
Hoinkis, J., Valero-Freitag, S., Caporgno, M. P., \& Pätzold, C. (2011). Removal of Nitrate and Fluoride by Nanofiltration a Comparative Study. Desalination and Water Treatment, 30(1-3), 278-288. http://doi.org/10.5004/dwt.2011.2103

Iran Meteorological Organization. (2016). Annual Percipitation. Retrieved from http:/www.irimo.ir/eng/ index.php

ISIRI. (2009). Chemical Specifications of Drinking Water. 5th ed. Tehran: Institute of Standards and Industrial Research of Iran (in Persian).

Mogheir, Y., Albahnasawi, A. M., \& Abuhabib, A. A. (2014). Optimal Use of Nanofiltration for Nitrate Removal from Gaza Strip Municipal Wells. IUG Journal of Natural and Engineering Studies, 22(2), 45-60.

Nightingale, E. R. (1959). Phenomenological Theory of Ion Solvation. Effective Radii of Hydrated Ions. The Journal of Physical Chemistry, 63(9), 1381-1387. http://doi.org/ 10.1021/j150579a011

Richards, L. A., Vuachère, M., \& Schäfer, A. I. (2010). Impact of $\mathrm{pH}$ on the Removal of Fluoride, Nitrate and Boron by Nanofiltration/Reverse Osmosis. Desalination, 261(3), 331337. http://doi.org/10.1016/J.DESAL.2010.06.025

Santafé-Moros, A., Gozálvez-Zafrilla, J. M., \& Lora-García, J. (2005). Performance of Commercial Nanofiltration Membranes in the Removal of Nitrate Ions. Desalination, 185(1-3), 281-287. http://doi.org/10.1016/J.DESAL.2005. 02.080

Statistical Center of Iran. (2011). Census Records 1390 (in Persian). Tehran: Statistical Center of Iran. Retrieved from https://goo.gl/d14rHv

Torabian, A., Harandi, M. S., Nabi Bidhendi, G. R., \& Ghadimkhani, A. (2009). Nitrate Removal from Drinking Water by Using Commercial Nanofiltration. Asian Journal of Chemistry, 21(1), 666-672.

Ward, M. H., Jones, R. R., Brender, J. D., de Kok, T. M., Weyer, P. J., Nolan, B. T., Villanueva, C. M., \& van Breda, S. G. (2018). Drinking Water Nitrate and Human Health: An Updated Review. International Journal of Environmental Research and Public Health, 15(7), 1557. http://doi.org/10.3390/ijerph15071557

Zhu, H., Feng, J., \& Teng, Y. (2017). The water quality monitoring of rural drinking water and analysis of improvement by nanofiltration membrane in Poyang Lake area, Integrated Ferroelectrics, 178(1), 138-143. http://doi.org/10.1080/10584587.2017.1325284 